\title{
Violência urbana, criminalidade e tráfico de drogas: uma discussão psicanalítica acerca da adolescência
}

Urban violence, criminality and drug trafficking: a psychoanalytic discussion about adolescence

Violencia urbana, la delincuencia y el tráfico de drogas: una discusión psicoanalítica sobre la adolescência

\author{
Andréa Máris Campos Guerra* \\ Camila Alves Noberto Soares** \\ Maria do Carmo de Melo Pinheiro*** \\ Nádia Laguárdia de Lima ${ }^{* * * *}$
}

\begin{abstract}
Resumo
Neste artigo, buscamos discutir a hipótese de que, na ausência do compasso de espera que a adolescência representa, o adolescente atravessado pela criminalidade parece encurtar o tempo de passagem da infância à vida adulta, num curto-circuito que quase suprime a passagem pela elaboração característica da adolescência. Como resposta sintomática, aliena-se ao saber do Outro do tráfico e se identifica com as figuras do crime como resposta às dificuldades que a puberdade lhe apresenta, como experiência de reencontro com o furo estrutural do sexual traumático. Para realizar essa análise, situamos conceitualmente a diferença entre puberdade e adolescência, e entre violência, agressividade e ato agressivo para a psicanálise, tendo como pano de fundo as mudanças quanto à composição do laço social na contemporaneidade.
\end{abstract}

Palavras-chave: Adolescência, Puberdade, Violência, Criminalidade, Contemporaneidade.

\footnotetext{
Doutora em Teoria Psicanalítica com Estudos Aprofundados em Rennes II (França), professora adjunta do Departamento e do Programa de Pós-graduação em Psicologia da UFMG, membro do GT Dispositivos Clínicos em Saúde Mental da ANPEPP e responsável pelo Diretório de Pesquisa Psilacs (Psicanálise e Laço Social no Contemporâneo) do CNPq/ UFMG.E-mail: aguerra@uai.com.br. Endereço: Alameda da Serra, 1374/2301 A - Vila da Serra, Nova Lima-MG. CEP 34000-000.

** Bolsista de apoio técnico na pesquisa citada, psicóloga (PUC Minas).E-mail: camila.alves.soares@gmail.com.

${ }^{* * *}$ Mestra em Psicologia pela UFMG, psicóloga (Fumec). E-mail: mcmpinheiro@yahoo.com.br.

${ }^{* * * *}$ Doutora em Educação (UFMG), psicóloga (UFMG), professora adjunta no Departamento de Psicologia UFMG. E-mail: nadia.laguardia@gmail.com.
} 


\begin{abstract}
In this article, we discuss the hypothesis that, in the absence of a period of standby that adolescence represents, the lawbreaker adolescent seems to shorten the transition from childhood to adulthood in a kind of short circuit that suppresses the passage of the preparation characteristic of adolescence. As a symptomatic response, they alienate themselves to the knowledge of the Other of the traffic and identify themselves with the figures of the crime as a response to the difficulties that the puberty presents, as a new meeting with the structural hole of sexual trauma. For this analysis, we place the conceptual difference between puberty and adolescence and between violence, aggression and aggressive act in psychoanalysis, with the changes in the composition of the social bond in the contemporary world as background.
\end{abstract}

Keywords: Adolescence, Puberty, Violence, Criminality, Contemporaneity.

\title{
Resumen
}

En este artículo, se discute la hipótesis de que, en ausencia del tiempo de espera que es la adolescencia, el joven delincuente parece acortar la transición de la niñez a la edad adulta en un cortocircuito que suprime la elaboración característica de la adolescencia. Como respuesta sintomática, ellos se alienan a el saber del Otro del tráfico y se identifican con las cifras de criminalidad en respuesta a las dificultades que presenta la pubertad, mientras la experiencia de la reunión con el agujero estructural del trauma sexual. Para realizar este análisis, se coloca conceptualmente la diferencia entre la pubertad y la adolescencia, y entre la violencia, la agresión y el acto agresivo hacia el psicoanálisis, y los cambios de la composición del vínculo social contemporáneo como fondo.

Palabras claves: Adolescencia, Pubertad, Violencia, Crimen, Contemporaneidad.

este artigo, buscamos discutir a hipótese de que, na ausência do compasso
de espera que a adolescência representa, o adolescente atravessado pela
criminalidade se cola ao saber do Outro do tráfico como resposta às
dificuldades que a puberdade lhe apresenta, como experiência de reencontro
com o furo estrutural do sexual traumático. Para isso, situamos inicialmente
a diferença entre puberdade e adolescência, entendendo o real na puberdade
como a irrupção de um órgão marcado pelo discurso na ausência de um saber 
sobre o sexo, sobre o que se pode fazer em face do outro sexo. Resta a cada um, então, inventar sua própria resposta. A adolescência, nesse sentido, seria a enumeração de uma série de escolhas sintomáticas em relação ao impossível da puberdade (Stevens, 2004).

Em seguida e a fim de precisar a diferença entre violência e agressividade, destacando seu uso no crime, buscamos em Lacan (1998) seu roteiro, localizando a violência mais articulado à pulsão de morte e a agressividade a seu tratamento. Porém, para além dessas questões conceituais e estruturais, descortina-se, na contemporaneidade, um novo cenário sobre o qual se funda o laço social. Dessa forma, tratamos de circunscrevê-lo a fim de destacar em que medida sua nova composição interfere na relação que adolescentes estabelecem com o crime, em especial com o tráfico.

Esperamos, dessa maneira, evidenciar nossa hipótese de que, contrariamente à constatação de uma ampliação da adolescência na atualidade, no caso dos jovens com quem realizamos nossas pesquisas, ${ }^{1}$ parece haver, antes, um curtocircuito entre infância e vida adulta, quase suprimindo o compasso de espera que a experiência da adolescência instala. Dessa maneira, soluções rápidas e instáveis se realizam no cenário do narcotráfico, compondo a sujeição de seus gozos e corpos a uma ordenação alienante ao Outro do crime. Vejamos como isso se processa.

\section{A adolescência na perspectiva psicanalítica}

Partimos do pressuposto de que a adolescência não é um termo psicanalítico. Eminentemente sociológico, biológico e psicológico, encontra na contemporaneidade sua mais pungente inscrição e repercussão. Freud fala em puberdade, não em adolescência, referindo-se às transformações que se dão no corpo, afetando o saber até então desenvolvido pela criança para lidar com o próprio corpo e com o mundo. ${ }^{2}$

Tornou-se comum considerar a adolescência como a fase compreendida entre a infância e a idade adulta, passagem necessária rumo à maturidade. Porém, tal qual a concebemos hoje, a adolescência nem sempre existiu (o que

\footnotetext{
Trata-se das pesquisas "A construção do laço social de jovens moradores de territórios com alto índice de criminalidade violenta" (Guerra, 2008), financiada pela Fapemig, Edital Universal-2008 e pelo FIP-PUC-CNPq, finalizando-se em novembro de 2009; e "A incidência do pai na subjetividade de jovens envolvidos com a criminalidade" (Guerra, 2010a), financiada pela Fapemig, Edital Universal - 2010 e pela PROPPG/UFMG, finalizando-se em fevereiro de 2012.

Diferentemente da adolescência também, que implica em um trabalho psíquico de significação imposto pelas mudanças corporais advindas da puberdade, a categoria juventude, por outro lado, é entendida como uma construção social, histórica, política e territorial, que não demanda necessariamente tal movimentação psíquica. Assim, esta última distinção, por se referir a uma análise macropolítica, não será aqui desenvolvida.
} 
faz de sua existência uma construção social). $O$ termo adolescência surge, em sua concepção moderna, entre o final do século XVIII e início do século XIX. Até então, a adolescência era confundida com a infância, e ambas abrangiam a ideia de dependência dos adultos no âmbito econômico, social e cultural (Ariés, 1981).

Além disso, será somente em meados do séculoXX que o adolescente começará a ser considerado perigoso e violento. Essa dimensão da juventude como problemática é maximizada pela publicação de Adolescence, obra do psicólogo americano Stanley Hall (1904, citado por Zeferino, 2009). Esse autor atribuiu a essa faixa etária qualidades antitéticas retomadas de Rousseau (hiperatividade e inércia, sensibilidade social e autocentrismo, intuição aguda e loucura infantil). Funda-se, assim, uma nova miragem social que se associa indelevelmente a essa fase da vida, considerada, na literatura clássica da Psicologia (Aberastury, 1971), uma etapa de "crise" a ser superada, com maiores ou menores avatares.

Freud (1987), como dissemos, utiliza o termo puberdade, descrevendo-a como um segundo tempo da sexualidade. $\mathrm{O}$ primeiro ocorreria na infância e retrocederia ou seria detido na latência; enquanto o segundo sobreviria com a puberdade, determinando a configuração definitiva da vida sexual. Também assevera que, com a chegada da puberdade, introduzem-se mudanças que levam a vida sexual infantil à sua configuração definitiva. A pulsão na infância era predominantemente autoerótica e, na puberdade, encontra o objeto sexual. Surge um novo alvo sexual para a conjunção de todas as pulsóes parciais: a zona genital, cuja primazia se estabelece então.

Na puberdade, também depararemos com o redespertar do Édipo e com a renovação dos conflitos edipianos e das fantasias incestuosas:

Contemporaneamente à subjugação e ao repúdio dessas fantasias claramente incestuosas consuma-se uma das realizações psíquicas mais significativas, porém também mais dolorosas, do período da puberdade: o desligamento da autoridade dos pais, unicamente através do qual se cria a oposição, tão importante para o progresso da cultura, entre a nova e velha geraçóes (Freud, 1974, p. 213).

E, diferentemente de sua primeira manifestação na infância, o redespertar do Édipo na puberdade tem a marca da interdição. Ele é reativado numa época mais além do recalque com esse novo elemento, que é a genitalidade. O desejo sexual reativa uma interdição, pondo em questão a impossibilidade de uma harmonia entre a pulsão sexual e a corrente terna sobre o mesmo objeto (Cottet, 1996). 
Freud (1974), então, observa que o jovem substitui a figura do pai pela do mestre. Ele acrescenta que tudo o que distingue a nova geração (tanto o que é portador de esperança quanto o que choca), tem como condição esse desligamento do pai. A crise em relação ao pai produz, assim, a nova geração. Nesse movimento, a função de interdição edípica e a abertura à possibilidade do exercício do desejo ampliam-se para sua concretização no pacto social (Pellegrino, 1987). Mais adiante, veremos que, na contemporaneidade, o mestre, na figura do capital, engendra novas relações sociais e simbólicas, produzindo consequências sobre a própria experiência da adolescência.

Lacan (2003a), por seu turno, avança na discussão da experiência da adolescência a partir de seu prefácio a "O despertar da Primavera". Ainda de acordo com Lacan (1975-1976), a subjetividade se constitui a partir do enlaçamento das três dimensões que compóem a realidade psíquica: o simbólico, o imaginário e o real. $\mathrm{O}$ registro simbólico designa a relação do ser falante com a estrutura da linguagem (significante); o registro imaginário, a relação do ser falante com a imagem; e o real, com o objeto. O complexo de Édipo seria o elemento que amarraria os três registros. $\mathrm{Na}$ puberdade, haveria um desatar desse nó que amarra os três registros da realidade psíquica. Diante da irrupção do real da puberdade, há um despedaçamento da imagem, como uma fratura do espelho, e o simbólico se mostra insuficiente para recobrir o real (Lima, 2009). Daí a importância da fantasia, como exercício psíquico, que favorece a construção de respostas a essa irrupção do real.

Segundo Stevens (2004), o real da puberdade, assim, pode ser articulado a três concepções de real em Lacan:

1) um primeiro conceito de real, articulável na disjunção entre a identificação simbólica e imaginária, acentuada pela experiência da adolescência em função do despedaçamento da imagem;

2) um segundo conceito de real como aquilo que irrompe, que não tem nome e que vem modificar a imagem, realizando-se no tempo do despertar da puberdade;

3) e o real como a não relação sexual, o impossível da estrutura que faz retorno na puberdade.

A adolescência se configuraria, pois, na enumeração de uma série de escolhas sintomáticas em relação a esse impossível, que é o real da puberdade. Com sua chegada, esse ponto de falha se presentifica, seja sob a forma do corpo sexuado e púbere, seja sob a forma do encontro com o Outro sexo, seja sob 
a forma da ausência de saber do Outro parental na transmissão significante de um referente sobre a diferença sexual ou sobre o gozo. Diante dessas impossibilidades que dão forma à falta real na puberdade, a adolescência se apresenta como a forma sintomática de resposta encontrada pelo púbere, na tentativa de nomear, enlaçar esse ponto de obscuridade (Stevens, 2004).

\section{$\frac{\text { Adolescência }}{\text { Puberdade }} \rightarrow \frac{\text { Sintoma }(\Sigma)}{\text { Real }(\Phi)} \rightarrow \frac{\text { Tentativas de nomeação (NNN) }}{\text { Não relação sexual }}$}

Lacan localiza, num certo uso do pai como semblante, o nome dessas tentativas de solução do púbere, que dão forma às suas possibilidades de articulação e composição de presença no laço social. Nessa introdução a "O despertar da primavera”, Lacan (2003a) nos ensina que o real do pai será o substrato com base no qual o púbere reconstituirá o nome próprio, conferindo novo corpo à sua imagem despedaçada. Afirma acerca do pai, na qualidade de semblante na adolescência, que

o pai tem tantos e tantos [nomes] que não há um que lhe convenha, a não ser o Nome do Nome do Nome. Não há Nome que seja seu Nome-Próprio, a não ser o Nome como ex-sistência. Ou seja, o semblante por excelência (Lacan, 2003a, p. 559).

Em outras palavras, o indizível que o pai porta, como seu gozo, seu pecado, será o elemento estrutural do qual o adolescente fará um uso que lhe convenha. Trata-se do uso da dimensão real que dá suporte à função paterna.

$\mathrm{Na}$ adolescência, estabelecer-se-á o nome próprio para além do Nomedo-Pai, contando com ele, mas para além da instalação da metáfora paterna. O reencontro com a falta de significante no campo do Outro3 convoca o pai a partir do ponto sobre o qual ele não legisla. Donde o sujeito precisar inventar uma nova nomeação, uma nova e mais definitiva inscrição no laço social a partir do Nome-do-Pai, sim, mas na forma de nomeação do gozo (entre simbólico e imaginário) (Guerra, 2010b).

Ora, o que nos interroga é justamente por que alguns adolescentes, na contemporaneidade, compóem essa nova inscrição no laço social com base na violência e ou na criminalidade. Assim, antes de desenvolvermos nossa hipótese, discutiremos como a psicanálise aborda a violência e a agressividade, diferindo os dois fenômenos.

\footnotetext{
3 Esse ponto de falta é denominado por Lacan de $\mathrm{S}$ de A barrado e corresponde ao ponto de falha estrutural da linguagem, operado sob a forma de um não saber na puberdade.
} 


\section{Sobre violência, agressividade e ato agressivo}

Sabemos que o ato agressivo pode ser uma via sintomática encontrada pelo adolescente para lidar com o real da puberdade, respondendo aos embaraços que encontra com o sexual (Guerra \& Pinheiro, 2011). Como "ato existencial ligado a uma relação imaginária” (Lacan, 1986a, p. 205), o ato agressivo estiraria, ao limite, a "agressividade originária presente no ato de desvencilhamento do Outro, característico da alienação primordial do sujeito à linguagem" (Lacan, 1986a, p. 198). O ato agressivo seria, portanto, uma exacerbação da agressividade estrutural que compõe a relação original do sujeito falante na relação com a alteridade.

Para Lacan (1998), a violência, por outro lado, é mais intimidação do que fato. Ela estaria associada, desde Freud (1976a; 1976b), à pulsão de morte, ao que não faz vínculo com a linguagem, ao que excede o corpo e a capacidade de representação do aparelho psíquico, e não à agressividade dirigida a alguém. Daí a compulsão à repetição como seu correlato, conforme o sujeito revive situações que não incluem possibilidade alguma de prazer e que nunca trouxeram satisfação, "algo que parece mais primitivo, mais elementar e mais pulsional do que o princípio do prazer” (Freud, 1976a, p. 37).

Ora, o que decidia o propósito da vida, para Freud (1976b, p. 94) e seu tempo, era o programa do princípio do prazer, que se encontrava, em geral, em desacordo com a civilização e suas regras, dadas suas exigências para garantir o pacto social. Entre a liberdade e a felicidade individuais e as exigências da civilização, formava-se um pacto que restringia a ação e a satisfação do homem. A "frustração cultural" (Freud, 1976b, p. 118) nesse cenário seria a causa da hostilidade contra a qual todas as civilizações teriam de lutar. Para a psicanálise, portanto, a violência implica a dimensão pulsional não tratada pela linguagem, estando articulada à noção de pulsão de morte freudiana.

E Lacan elucida essa diferença entre agressividade e violência ao associar a violência à pulsão de morte e a agressividade à relação especular constitutiva do eu. Quando Freud (1976a, p. 69) propõe a dualidade pulsional entre pulsão de vida e pulsão de morte, aloca à pulsão de vida a dimensão do que renova a vida, operando de maneira construtiva ou assimilatória, enquanto a pulsão de morte seria destrutiva ou dissimilatória. Por isso o aparelho psíquico tende à repetição: ele visa a encontrar uma tradução, uma vinculação para esse excesso.

Por isso também, podemos pensar com Lacan, a violência falará desse intratável, enquanto a agressividade não. A agressividade seria a força necessária para que o sujeito, inscrito seu desejo como desejo do Outro, possa desse Outro se desvencilhar. 
$\mathrm{Na}$ origem, antes da linguagem, o desejo só existe no plano da relação imaginária do estado especular, projetado, alienado no outro. A tensão que ele provoca é então desprovida de saída. Quer dizer não tem outra saída, [...] senão a destruição do outro (Lacan, 1986a, p. 197-198).

A agressividade originária, assim, seria um primeiro tratamento à pulsão de morte, ao real pulsional. Manifestar-se-ia como tentativa de diferenciação em relação ao outro. Se a entrada da ordem simbólica é bem-sucedida, esse tratamento se dá pela via da palavra. Se a palavra não é suficiente para tratar esse excesso, $\mathrm{o}$ ato agressivo surge no lugar da palavra que não advém. Prescindindo da palavra, portanto, a agressividade pode se presentificar em ato, quando ao sujeito não restam outros recursos ou desvios. Assim, violência, agressividade e ato agressivo são três fenômenos diferentes que exigem dispêndios também diversos de energia psíquica junto às ações civilizatórias e a seu risco de desintegração.

Diante dessa formulação, podemos nos perguntar o que se passa com os adolescentes em conflito com a lei, cuja presença no laço social se manifesta, muitas vezes, pela violência engendrada pela presença e participação na criminalidade. Em especial, os jovens envolvidos com o tráfico de drogas nos trazem uma relação com a violência, normatizada pelas regras que compõem a lida com o "movimento" (tráfico), praticamente institucionalizando-a como sistema de vida. "Não dá para conversar? A conversa dá. É tatatatatatata até não aguentar" (Guerra, 2011, p. 243). ${ }^{4} \mathrm{O}$ que podemos dizer sobre isso? Tentemos entender a lógica do laço social na contemporaneidade para conseguirmos caminhar um pouco mais.

\section{Sobre o laço social na contemporaneidade}

Em seu texto "Pacto edípico e pacto social", Pellegrino (1987) propõe, com base no texto freudiano, uma tese original sobre o laço social, assentada na hipótese de que há uma correlação entre a queda do pacto edípico e a quebra do pacto social. Segundo Lacan (1995), é pelo consentimento com a interdição que decorre a potência ordeira das pulsões. Originalmente estamos imersos no caos pulsional que a língua materna corporifica. Sobre a língua materna, deita-se a linguagem, estruturada a partir do Édipo, como forma de civilizar o que ali se faz possível partilhar na composição do laço com a alteridade. Assim, a criança que internaliza a interdição de gozar do corpo da mãe, submetendo-

\footnotetext{
Trecho extraído de conversação realizada na pesquisa "A incidência do pai na subjetividade de jovens envolvidos com a criminalidade" (GUERRA, 2011), financiada pela Fapemig e PROPPG/UFMG.
} 
se ao "não do pai" e renunciando à onipotência do seu desejo para adequar-se às exigências do princípio de realidade, cumpre o acordo que a tornará parte da sociedade humana. A submissão à lei é estruturante conforme organiza o sujeito diante da renúncia ao gozo e o insere na lógica simbólica da castração, integrando-o no circuito de desejo e de intercâmbio social.

Ao mesmo tempo em que o incesto é proibido, abre-se a possibilidade para outras escolhas. O pacto edipiano tem, portanto, mão dupla: a criança perde por um lado, mas ganha por outro. Em troca da renúncia que lhe é imposta, e mesmo exigida, tem o direito de receber nome, filiação, lugar na estrutura de parentesco, acesso à ordem simbólica, enfim, o que se faz necessário para se inserir e participar da cultura. Assim, segundo Pellegrino (1987), o pacto edípico garante e sustenta o pacto social, mas este, por retroação, confirma e afirma o primeiro.

Se esses valores são desrespeitados, a consolidação social é injusta. Para Pellegrino (1987), quando, no pacto social, a sociedade não provê as condições materiais mínimas para presença e participação na vida pública, teríamos uma via de mão única. O pacto teria, nesse caso, mão única, podendo romperse, o que implicaria graves consequências para o arranjo civilizatório. Atos agressivos poderiam advir dessa ruptura. Zenoni (2007), apoiado em Lacan, fala de uma reação de impostura e traição em referência à lei, quando o pai não se interpõe entre mãe e filho ou quando a mãe não divide seu desejo entre o filho e o pai.

Cabe aqui, entretanto, uma ressalva, porque sabemos que nem toda violência é partidária de uma ruptura ou de um deslocamento do significante Nome-do-Pai, já que existem violências reguladas pela lei. À quebra do pacto, um sujeito pode responder sem nenhuma ruptura em seu mundo interno. Pode, pelo contrário, agir totalmente determinado pelos significantes da civilização, regidos pelo Nome-do-Pai, buscando ou restaurar o pacto ou retribuir a violência sofrida. Há uma violência necessária ao estabelecimento e à manutenção da lei e que, portanto, trabalha para a manutenção do pacto social e não somente em sua ruptura.

Nesse sentido, entendemos que Pellegrino nos traz uma leitura interessante, mas há de se ter cuidado com o termo ruptura proposto por ele, pois uma ruptura de fato levaria à instalação e ao desencadeamento de uma psicose, o que não parece ser o caso. Talvez possamos dizer que o significante paterno, o Nome-do-Pai, está lá, só que não opera da mesma maneira. Assim, não se trata da perda ou ruptura do marco estrutural que condiciona a entrada do sujeito na linguagem, tal como Lacan (1985) apresenta em "O seminário, 
livro 3", ao falar da psicose, ou seja, da posição que o sujeito ocupa frente à castração. Mas, sim, de uma quebra nas condiçôes simbólicas que agenciam o pacto social.

Assim, no contexto contemporâneo, sobretudo para os jovens, o pacto social se mostra cada vez mais inconsistente. $\mathrm{O}$ discurso que vigora parece não mais veicular e fazer valer os interditos fundamentais que fundam o laço social, já que as referências culturais não se sustentam como ideais, estão aquém, ou mesmo além, da aliança com o pai simbólico. Assim, diante das rupturas que o pacto nos aponta, somos instigados a pensar quais seriam os elementos que estariam norteando as condutas dos jovens. E o que vemos na atualidade, sem grande esforço, são as leis do mercado ocupando, ou mesmo usurpando, o lugar antes reservado à lei do pai. $\mathrm{O}$ capital se tornou o grande mestre contemporâneo, segundo Lacan (2003b). Consequentemente, em uma de suas facetas, o interdito é substituído por seu oposto: a transgressão, a superação dos limites, a permissividade, a exigência de felicidade, a ilusão de usufruto do objeto.

Diferentemente do contexto freudiano, vivemos sob a égide do excesso, do consumismo, do desfrute, do deleite a qualquer preço. Na falta da segurança coletiva, pactuamos com a satisfação individual (Bauman, 1998). Ligado à busca do prazer imediato e incessante, o supereu se coloca como uma palavra de ordem, para além do prazer, exigindo a satisfação obtida por meio da fruição da pulsão de morte. Precisamos considerar que, se em Freud, a culpabilização do gozo aparece como resultado da ação do supereu, isso hoje não é mais sustentável como um universal. Os processos de socialização contemporâneos alteraram-se.

Nessa perspectiva, Zizek (2003, p. 5) propõe que

não estamos mais diante da velha situação psicanalítica descrita por Freud por meio da ideia do supereu. Situação que articulava civilização e repressão, ao insistir que não podemos gozar porque internalizamos proibições sexuais e uma autoridade paterna que culpabiliza o prazer sexual.

$\mathrm{Na}$ contemporaneidade, não se trata mais do recalque das monções pulsionais, mas do gozo como uma obrigação, cabendo a cada um encontrar seu modo de fruição. Isso nos instiga a procurar entender que tipo de pacto social estaria vigorando hoje, diante do que propôs Pellegrino (1987).

Entendemos que esse pacto se funda agora em outras bases, alicerçado pela lógica do consumo e do imperativo do gozo, estando o sujeito refém de um supereu tirânico e gozador, sendo tais mudanças decorrentes da 
nova configuração político-social da contemporaneidade. Saflate (2010, p. 5) observa que "ao invés da sociedade de produção, devemos compreender a contemporaneidade e seus traços a partir da temática da sociedade de consumo". A mudança de paradigma da sociedade industrial da produção para a sociedade pós-industrial do consumo traz consequências, sobretudo pelo fato de que os modos de alienação necessários para entrarmos no mundo do trabalho não são inteiramente simétricos aos modos de alienação presentes no mundo do consumo. Enquanto o mundo capitalista do trabalho é sustentado pela ética do ascetismo e da acumulação, o mundo capitalista do consumo se rende à ética do direito ao gozo, já que precisa da procura ao gozo, para provocar a incessante produção das possibilidades de escolha no universo do consumo.

Incessante e inadiável, tomado como imperativo na contemporaneidade, o gozo, infinito e mortífero do qual o sujeito se vê refém, pode incitar o sujeito a atos agressivos contra si mesmo e ou contra o outro. Esses atos podem ser pensados como tentativas de se esvaziar desse excesso, predominantemente pelo viés imaginário na relação com a alteridade. Daí a possibilidade de se considerarem tais atos como soluções sintomáticas na adolescência, conforme evidenciam e denunciam novas configurações de laço social. Como, enfim, podemos então articular adolescência, violência e criminalidade nesse enquadre contemporâneo?

\section{Adolescência e criminalidade: ausência do compasso da espera}

Assim, apoiadas na hipótese de Lima (2009), propomos que, no caso dos jovens atravessados pela experiência com o tráfico de drogas, há uma redução ou mesmo uma supressão do compasso de espera, cuja moratória social favorece a elaboração da puberdade, quando o sujeito é convocado a se decidir com relação às suas escolhas. É exigido dele uma posição sexuada, que envolve o enfrentamento de seu destino. Nesse momento, antes do "despertar da primavera", ele recorre às fantasias como forma de compor uma resposta à falha estrutural de saber sobre o real sexual que se reapresenta na puberdade, como vimos.

Ao questionar o desejo do Outro, o sujeito constrói uma fantasia que, se por um lado, envolve um recobrimento da castração, por outro, envolve uma construção própria, que o leva à separação da posição de objeto da fantasia materna. Ao construir uma resposta fantasmática ao enigmático desejo do Outro, o sujeito tece o seu destino. Barros (1996) ressalta a dimensão paradoxal da fantasia: ela só é possível a partir da separação, ao mesmo tempo em que tenta encobrir o que provocou a separação, ou seja, o que se revelou como 
opaco no próprio gozo do sujeito e no desejo do Outro. Na adolescência, há a possibilidade de um encontro que rompe a continuidade edipiana, pois o sujeito, ao se confrontar com aquilo que escapa à determinação significante, ou seja, seu próprio gozo desconhecido, pode se responsabilizar por essa nova forma de gozar.

Revelou-se, pois, no discurso dos jovens, uma precocidade com relação à entrada na vida adulta. Ao contrário do que comumente se observa na dilatação da adolescência na contemporaneidade, podemos dizer que os jovens com quem conversamos passam pela puberdade, mas não pela adolescência (Lima, 2009). O termo puberdade designa um acontecimento no corpo que tem o efeito de um trauma, no sentido de um confronto com algo novo que escapa à significação, pois "não existem palavras" para dizer desse encontro com o real do sexo. Assim, a puberdade é um fenômeno universal. O termo adolescência, como vimos, é uma invenção social. Segundo Calligaris (2000), o termo não apresenta uma definição clara, e essa indefinição acaba por instaurar nessa fase da vida uma moratória forçada, pois não se sabe exatamente o que esperar do jovem para que ele possa exercer seus papéis na sociedade.

$\mathrm{Na}$ nossa cultura, não existem rituais de passagem que marquem a saída da infância e a entrada na fase adulta. Assim, a adolescência é considerada por Calligaris (2000) como um período intermediário entre a infância e a fase adulta, um período de moratória, no qual o jovem adia a sua inserção na cultura, "preparando-se" para ela. Apesar de apresentar todas as condiçóes para o exercício da vida sexual, profissional e afetiva, a sociedade não permite que ele exerça esses papéis. A fase da adolescência é, pois, marcada por um "não lugar", um intervalo, um período de espera para a entrada no mundo social. Se esse período de moratória imposto pela sociedade pode dificultar a inserção social do jovem, sabemos que um intervalo entre o despertar do real da puberdade e a assunção de uma posição sexuada se faz necessário.

No discurso dos jovens, a adolescência como "moratória" parece não existir. No despertar da puberdade, quando a sexualidade "faz furo no real", esses jovens passam a ter acesso fácil à vida sexual, ao crime e às drogas, que "oferecem" uma solução rápida e eficaz para o encobrimento da falta estrutural, desvelada nesse momento. Logo, ao entrar na puberdade, quando a escolha de uma posição sexuada ainda não está bem definida, muitos desses jovens já se tornam pais, passam a viver com uma companheira, assumem a vida financeira da família de origem, como "homem" da casa, e, por vezes, instalam-se no crime. As exigências impostas pelas condições de vida desses jovens forçam uma urgência de resposta do sujeito. Essa rápida ascensão à condição de adulto não permite, portanto, a vivência da "adolescência", no sentido de um 
tempo de moratória, como tempo necessário para a construção de fantasias, que levam ao adiamento de uma resposta imediatista e à escolha sustentada pelo desejo.

Ao se deparar com o que faz furo no saber, o sujeito adolescente precisa construir um saber sobre si que possibilite alojar o seu gozo e sustentar seu desejo. Para isso, é necessário um “compasso de espera”, certa moratória, que permita ao sujeito construir uma resposta sintomática, fazer um arranjo particular com o qual ele organizará sua existência, sua relação com o mundo e com o gozo.

Assim, diante da falha de saber no real, que se presentifica para todos, a trajetória de alguns jovens parece conduzi-los a estratégias de inscrição (e não de segregação) no laço social pela via do crime. Nesse sentido, diante de fenômenos característicos da puberdade (como o esfacelamento da imagem, a impossibilidade simbólica de dizer das mudanças físicas e afetivas e do real que irrompe com o encontro com a sexualidade - ou castração), o saber do crime poderia ser pensado como um Outro que garante uma resposta e uma inscrição no laço social. E, conforme inclua atos agressivos sua composição, pode ainda se configurar em uma via suplementar de escoamento pulsional. Pressupomos, pois, que o jovem, na busca de afirmação de si, tempo da reafirmação de posições e escolhas, endereça-se a um Outro do saber (mundo do crime) e produz um saber possível a partir daí sobre si mesmo (complementarmente podendo fazer desse arranjo uma solução para o excedente pulsional que o atravessa). O Outro do crime prometeria resposta ao furo da estrutura, pois ofereceria um sistema normativo e regulador, ainda que não dialetizável, que funcionaria como contorno ao real pulsional em jogo na puberdade.

O laço grupal que se estende a partir daí parece se sustentar pela identificação. Opera, assim, como efeito da identificação com o líder, no nível do ideal do eu, e efeito da identificação egoica, entre os eus de seus membros, compondo um arranjo no qual os jovens buscam ficar "intrujados" com o patrão (como ideal a ser alcançado) e "colados com" os colegas (como efeito da identificação imaginária). ${ }^{5}$ No eixo imaginário, encontram-se sujeitos que se veem como reflexos especulares uns dos outros, o que transparece na maneira de usar as gírias-código do tráfico e as roupas "pichadas" que os identificam aos traficantes. Por outro lado, essa especularização também constrange o sujeito a um sem-espaço para si, que

5 Expressōes encontradas nas entrevistas realizadas na pesquisa "O laço social entre jovens moradores de territórios com alto índice de criminalidade violenta” (GUERRA, 2009), financiada pela Fapemig e pelo FIP/PUC Minas. 
pode culminar na desconfiança e na agressividade. Verifica-se, assim, uma instabilidade e, ao mesmo tempo, uma rigidez, na manutenção dos laços, que é acirrada pela liquidez das relações contemporâneas (Guerra et al., 2009).

Ao contrário da regulação por um pai morto, simbolizado pelo totem e pelo tabu que garantem as regras de boa convivência, deparamo-nos, de um lado, com um exacerbamento do poder totêmico de um pai vivo e gozador, figurado no líder do tráfico. Este é idealizado e temido pelo horror que provoca e pela lei caprichosa e unilateral que funda e mantém pela violência. E, por outro lado, observamos o deslocamento do tabu para "as leis do tráfico" que garantem, diferentemente do mito da horda primeva, o gozo privado de cada um na medida de sua inserção na hierarquia do crime. É o pai vivo quem garante o banquete totêmico, regado a drogas e armamento pesado na devoração dos corpos. A vida, nessa lógica, é garantida pela contramorte do outro: "ou você mata ou você morre, não tem saída".

\section{Conclusão}

Parece que se insinuam um tempo e uma geopolítica em que colidem diferentes fatores, multifacetando a subjetivação do jovem "atravessado" pela criminalidade violenta. Longe de um campo farto de escolhas, parecenos que a resposta do crime nasce sem conferir intervalo para que alguma dúvida se instale e produza uma resposta pelo qual o adolescente consiga se responsabilizar, decidir de fato. Além disso, atravessado pelo corpo adolescente e pela urgência de satisfação, o jovem parece não considerar esses intervalos simbólicos e, antes, atuar na imediatez do cotidiano da sobrevivência. Desde que inserido na trama imaginária do Outro do tráfico, parece não contar mais como sujeito que se apropria de suas próprias experiências, mas se apresenta como corpo-objeto que se lança na manutenção desse "sistema". Nesse sentido, não difere do corpo-produção acerca do qual Marx (1983) advertia em sua discussão sobre a alienação do trabalhador (salvo por se anestesiarem com adiçôes diversas, cultuar o prestígio comunitário que ganham e atuarem ininterruptamente com seus corpos-escudos expostos diariamente à morte). Elementos contemporâneos da organização do narcotráfico por influência do capital globalizado. Difícil, nessa gestão dos corpos pelo risco, encontrar "a fórmula e o lugar" (Lacadée, 2011) para uma nova composição do laço social.

Apostar numa ação de reescrita do gozo do adolescente, implica, então, num caminho duplo. De um lado, percurso que o implique em sua resposta 
ao não saber-fazer com o real sexual do corpo púbere e, por outro, que implique a civilização diante dos recursos que dispõe para remendar sua trama simbólica enfraquecida. A aposta consiste em fazer com que o sujeito não se extravie do seu desejo, mas possa escrever, como resposta, um novo modo de lidar com ele.

\section{Referências}

Aberastury, A. (1971). Adolescência. Porto Alegre: Artes Médicas.

Ariés, P. (1981). História social da criança e da família (Dora Flaksman, Trad.). (2a ed.). Rio de Janeiro: Livros Técnicos e Científicos.

Barros, M. R. C. R. (1996). Adolescência: quê despertar? In: H. C. Ribeiro \& V. Pollo (orgs.). Adolescência: o despertar. Revista Kalimeros. (pp. 69-80). Escola Brasileira de Psicanálise. Rio de Janeiro: Contra Capa Livraria.

Bauman, Z. (1998). O mal-estar da Pós-modernidade. Rio de Janeiro: Jorge Zahar.

Calligaris, C. (2000). A adolescência. São Paulo: Publifolha.

Cottet, S. (1996). Estrutura e romance familiar na adolescência. In: H. C. Ribeiro \& V. Pollo (orgs.). Adolescência: o despertar. Revista Kalimeros (pp. 07-20). Escola Brasileira de Psicanálise. Rio de Janeiro: Contra Capa Livraria.

Freud, S. (1987). Três ensaios sobre a teoria da sexualidade: transformações da puberdade. In: Um caso de histeria e três ensaios sobre a sexualidade. Ediçãa Standard Brasileira das Obras Psicológicas Completas de Sigmund Freud (ESB). (J. Salomão, trad., Vol. 7, pp. 196-217). Rio de Janeiro: Imago. (Trabalho original publicado em 1905.)

Freud, S. (1974). Algumas reflexões sobre a psicologia do escolar. In: Totem e tabu e outros trabalhos. Edição Standard Brasileira das Obras Psicológicas Completas de Sigmund Freud (ESB). (J. Salomão, trad., Vol. 13, pp. 281-288). Rio de Janeiro: Imago. (Trabalho original publicado em 1914.)

Freud, S. (1976a). Além do princípio do prazer. In: Edição Standard Brasileira das Obras Psicológicas Completas de Sigmund Freud (ESB). (J. Salomão, trad., 
Vol. 18, pp. 17-89). Rio de Janeiro: Imago. (Trabalho original publicado em 1920.)

Freud, S. (1976b). O mal-estar na civilização. In: Edição Standard Brasileira das Obras Psicológicas Completas de Sigmund Freud (ESB). (J. Salomão, trad., Vol. 21, pp. 81-177). Rio de Janeiro: Imago. (Trabalho original publicado em $1930[1929]$.)

Guerra, A. M. C. (2008). A construção do laço social de jovens moradores de territórios com alto indice de criminalidade violenta. Projeto de Pesquisa, Fapemig/ FIP-PUC Minas/Universidade Federal de Minas Gerais, Belo Horizonte.

Guerra, A. et al. (2009). O desafio do trabalho com jovens envolvidos com a criminalidade: oficinas comunitárias como estratégia inovadora na Justiça Social. Cartas de Psicanálise, CEPP-Vale do Aço/Unipac, a. 4, 2 (6), 200-209.

Guerra, A. M. C. (2010a). A incidência da figura paterna na subjetividade de jovens envolvidos com a criminalidade. Projeto de Pesquisa, Universidade Federal de Minas Gerais/Fapemig, Belo Horizonte.

Guerra, A. M. C. (2010b). A psicanálise e o jovem envolvido com a criminalidade: considerações sobre o laço e o semblante no uso do pai. In: C. T. Heleno \& S. M. Ribeiro, Criança e adolescente: sujeitos de direitos. (pp. 135-153). Belo Horizonte: Conselho Regional de Psicologia.

Guerra, A. M. C. (2011). Crítica de uma morte anunciada. In: C. Garcia (org.). Interfaces. (pp. 239-251). Belo Horizonte: Ophicina de Arte \& Prosa.

Guerra, A. M. C. \& Pinheiro, M. C. M. (2011). A escrita da violência na adolescência. In: Anais, 6 Congresso Nacional de Psicanálise da Universidade Federal do Ceará. Fortaleza: UFC.

Lacadée, P. (2011). O despertar e o exílio: ensinamentos psicanalíticos da mais delicada das transiçôes: a adolescência. Rio de Janeiro: Contra Capa Livraria.

Lacan, J. (1998). A agressividade em psicanálise. In: Escritos. (pp. 104-126). Rio de Janeiro: Jorge Zahar. (Original publicado em 1948.)

Lacan, J. (1986a). O Seminário, livro 1: os escritos técnicos de Freud. Rio de Janeiro: Jorge Zahar. (Lições originalmente pronunciadas em 1953-1954.)

Lacan, J. (1985). O Seminário, livro 3: as psicoses. Rio de Janeiro: Jorge Zahar. (Liçôes originalmente pronunciadas em 1955-1956.) 
Lacan, J. (1995). O Seminário, livro 4: a relação de objeto. Rio de Janeiro: Jorge Zahar. (Lições originalmente pronunciadas em 1956-1957.)

Lacan, J. (2003a). Prefácio a "O despertar da primavera". In: Outros Escritos. (pp. 557-559). Rio de Janeiro: Zahar. (Original publicado em 1974.)

Lacan, J. (2003b). Televisão. In: Outros escritos (pp. 508-543). Rio de Janeiro: Jorge Zahar. (Entrevista transmitida pela Radiodiffusion-Télévision Française $(R T F)$, em 9 e 16 de março de 1974.)

Lacan, J. (1975-1976). Livre XXII, RSI. Ornicar?, nº. 02-05. Paris: ECF. (Lições originalmente pronunciadas em 1974-1975)

Lima, N. L. (2009). A escrita virtual na adolescência: os blogs como um tratamento do real da puberdade, analisados a partir da função do romance. Tese de doutorado, Universidade Federal de Minas Gerais, Belo Horizonte.

Marx, K. (1983). O Capital: crítica da economia politica. (R. Barbosa \& F. R. Kothe, trad.). São Paulo: Abril Cultural.

Pellegrino, H. (1987). Pacto Edípico e Pacto Social. In: L. A. Py (org.). Grupo sob grupo. (pp. 195-205). Rio de Janeiro: Rocco.

Saflate, W. (2010). O moderno e o contemporâneo. Recuperado em 25 de outubro de 2010, de http://geocities.com/wladimirsaflate/vladi073.htm.

Stevens, A. (2004). Adolescência, sintoma da puberdade. Clínica do contemporâneo. Revista Curinga. Escola Brasileira de Psicanálise-Seção Minas, 20, 27-39.

Zeferino, C. F. O. (2009). Fica vivo!: uma resposta civilizatória. Trabalho de Conclusão de Curso, Pontifícia Universidade Católica de Minas Gerais, Betim.

Zenoni, A. (2007). Versões do Pai na psicanálise lacaniana: o percurso do ensinamento de Lacan sobre a questão do pai. Psicologia em Revista. PUC Minas Gerais, 13 (1), 15-26.

Zizek, S. (2003). O hedonismo envergonhado [Caderno Mais!]. Jornal Folha de São Paulo. Recuperado em 12 de novembro de 2012 de http://www1. folha.uol.com.br/fsp/mais/fs $1910200303 . h t m$. 